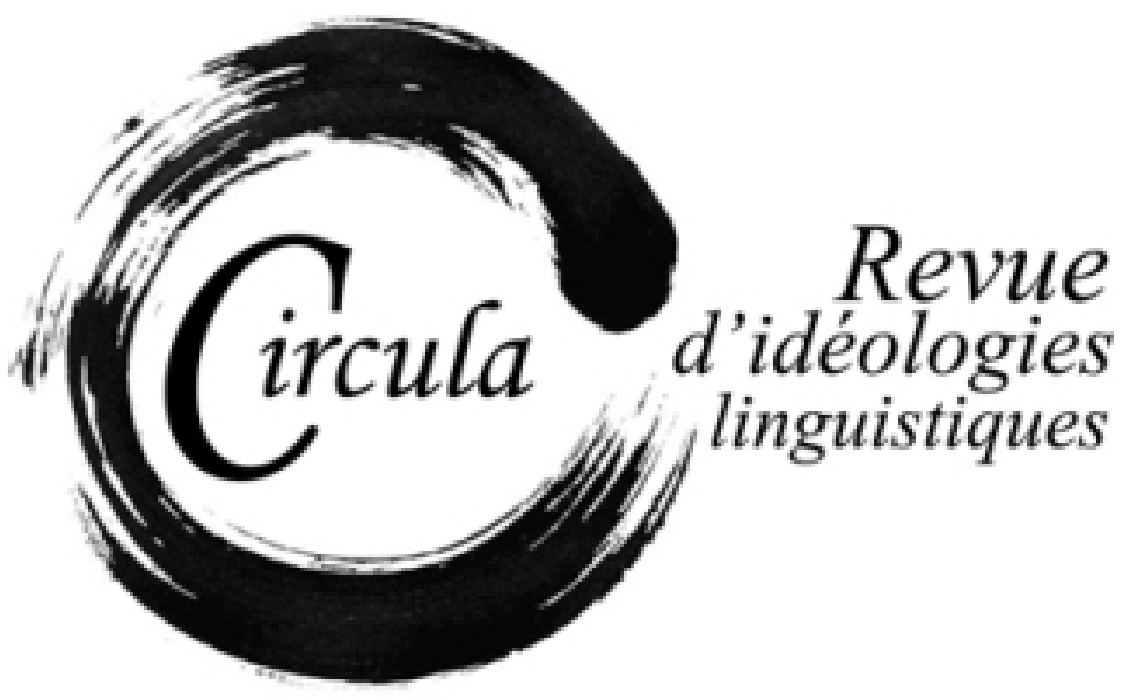

TITRE: IDEOLOGÍAS LINGÜÍSTICAS EN LA PRENSA DE LA TRANSICIÓN: ANÁLISIS DE LAS CARTAS AL DIRECTOR PUBLICADAS EN EL PAÍS

AUTEUR: NARCíS IGLÉSIAS, UNIVERSIDAD DE GIRONA

Revue: CIRCULA, NUMÉRO 10

PAGES: $1-21$

ISSN: 2369-6761

URI: HTTP://HDL.HANDLE.NET/11143/16771

DOI: HTTPS://DOI.ORG/10.17118/11143/16771 


\section{Ideologías lingüísticas en la prensa de la Transición: análisis de las cartas al director publicadas en El País}

Narcís Iglésias, Universidad de Girona narcis.iglesias@udg.edu

Resumen: La Transición supuso poner fin al monolingüismo instaurado por el franquismo y abrir una etapa de reconocimiento a la diversidad lingüística. A pesar de ser un período de gran transcendencia, son más bien escasos los estudios dedicados al tema. En este artículo me he limitado a estudiar las ideologías lingüísticas de los lectores del periódico El País durante la Transición, expresadas a través de su sección de cartas al director. Las opiniones de los lectores no presentan un tono uniforme, sino que abarcan todo tipo de planteamientos, a menudo antagónicos, desde aspectos generales y teóricos (lengua nacional, dialectos, oficialidad...), hasta temas más concretos, tales como la enseñanza o los derechos lingüísticos, más habituales durante los primeros años de democracia. En términos generales, en las cartas al director publicadas en El País dominan las opiniones de los lectores que expresan sus objeciones hacia la diversidad lingüística.

Palabras clave: ideologías lingüísticas; diversidad lingüística; Transición; El País; cartas al director

Abstract: The Spanish transition meant the end of the monolingualism established by the Francoist regime and the beginning of a period of recognition of language diversity. Despite the importance of the issue, during what was a crucial period, there is relatively little work dedicated to it. This article focuses on the language ideologies of the readers of El País, as expressed in the newspaper's letters section, during the Spanish transition. The readers' opinions do not have a uniform tone, but they cover, in a quite often agonistic way, a wide range of issues, from general and theoretical ones (national language, dialects and officialdom...), to more concrete ones, such as education and linguistic rights, which was more usual during the first years of democracy. In general terms, a vast majority of opinions defended in the letters to the editor of El País raise objections to language diversity.

Key words: language ideologies; language diversity; Spanish transition; El País; letters to the editor 


\section{Introducción: objeto de estudio y planteamiento de la investiga- ción}

Los grandes cambios sociopolíticos son momentos privilegiados para el análisis de la evolución de las lenguas. La España contemporánea, marcada por el régimen de Franco y por la democracia nacida con la Constitución de 1978, ha pasado en pocas décadas de diferencia por dos modos bien distintos de tratar la diversidad lingüística dentro del Estado. El franquismo se fundamentó desde sus inicios en una ideología uniformista, basada en la exaltación de una única lengua nacional' ${ }^{1}$ y no fue hasta la Transición cuando se fraguó el fin del monolingüismo que caracterizó la dictadura para dar paso a una democracia que se plantearía la diversidad lingüística. En la historiografia española se ha subrayado que la Constitución de 1978, un momento crucial de la Transición, representa la primera vez en la historia de España en que se reconoce la diversidad lingüística (González Ollé 1978 ; Brumme 2006). En el plano legal e institucional, varias lenguas de España consiguieron cambiar su estatus al adquirir la condición de cooficialidad en sus respectivos territorios, lo que ha permitido que en democracia se hayan promovido las lenguas no castellanas a todos los niveles públicos e institucionales, aunque en grados diferentes según cada comunidad².

La etapa de la Transición que se abrió despúes de la muerte del general Franco (1975) fue un momento de cambio (o de ruptura según se interprete) a todos los niveles, no solo para la obtención de derechos fundamentales en toda democracia (derecho a voto, libertad de expresión, separación entre Estado e Iglesia, etc.), sino también para el fomento y creación de nueva cultura política ciudadana, pilar fundamental de las democracias individuales, en la que los medios de comunicación de la época, y especialmente la prensa, tuvo una influencia determinante 3 . En un momento de profundas transformaciones de la sociedad española a muchos niveles, la prensa jugó un papel determinante a la hora de crear un estado de opinión que contribuyera a superar la dictadura franquista y a poner los cimientos de la naciente democracia española. A menudo se habla de la importancia

1. Tal y como ha escrito Brumme (2004: 948) en la Historia de la lengua española dirigida por Rafael Cano: "Durante la dictadura (1939-1975) se derogó toda la legislación relativa a la emancipación de las 'lenguas regionales', se prohibió su uso público y se coaccionó a los hablantes con la ayuda de repetidas invectivas y eslóganes como "Si eres español habla en español" o "Si eres español habla la lengua del Imperio". En la historiografía vasca y catalana se ha estudiado con profundidad la persecución contra las .lenguas no castellanas: véase, por ejemplo, Benet (1995), Sánchez Erauskin (1994) o Gallofré (1991). Para una panorámica crítica sobre el franquismo y las lenguas, así como las políticas lingüísticas contemporáneas llevadas a cabo en Cataluña, véase Iglésias (2018).

2. Obviamente, sobre las políticas lingüísticas desarrolladas desde la Transición, no hay unanimidad entre los especialistas. Véase, por ejemplo, Castillo Lluch y Kabatek (2006). Por otra parte, algunos de los principales sociolingüistas catalanes han considerado que la España democrática no ha dejado de ser un Estado monolingüe, que también ha legislado a favor del castellano; véase, por ejemplo, Bastardas y Boix (1994) o Joan Marcet (2013). Desde hace unos años, han ido apareciendo autores partidarios de limitar las políticas lingüísticas de las comunidades autónomas bilingües y de reclamar para el estado una política unitarista; véase, por ejemplo, Pericay (2007)

3. Se suele considerar que la Transición empieza en 1975 con la muerte de Franco y acaba en 1982, con la mayoría absoluta del PSOE (Tusell, 1997). Sin embargo, no todos los especialistas comparten esta periodización; sobre la variedad de aproximaciones históricas al período en cuestión, véase la revisión de Martín (2014). 
del "Parlamento de Papel" (términino ya acuñado en la época), es decir, de la influencia de la prensa española a la hora de preparar la sociedad para la democracia. Durante la Transición, la mayoría de periódicos, incluidos los que fueron próximos o fieles al régimen franquista, defendieron una democracia de corte liberal y representativa, respetuosa con algunas instituciones, normas legales y élites de la dictadura. La prensa, pues, se convirtió en un medio fundamental para encauzar las reformas políticas democratizadoras que se llevarían a cabo durante la Transición.

El interés académico por este período sigue permanentemente abierto, con frecuentes aportaciones desde ángulos muy varios en lo que se refiere a la historia política, social o cultural (Ysàs, 2013). En cuanto a las lenguas se refiere, en cambio, todavía no ha habido estudios monográficos de lo que representó la Transición. Así por ejemplo, en obras de referencia que se ocupan de la historia de la lengua española hasta el periodo contemporáneo, o bien no se llega a tratar el período, o bien el tratamiento es bastante tangencial ${ }^{4}$. Algo semejante ocurre en estudios que se han propuesto relatar a partir de los periódicos los vaivenes de la Transición 5 . En términos generales, pues, la literatura académica no ha integrado en su narrativa los cambios que se abrieron durante la Transición en cuanto a las lenguas se refiere, más allá de subrayar los cambios legales, como el estatus de cooficialidad que consiguen varias lenguas en sus respectivos territorios.

La poca atención que hasta el momento el mundo académico le ha dedicado contrasta con la abundante presencia de información y opinión sobre las lenguas en la prensa española. En los más variados periódicos españoles de diferentes ciudades, se publicaron numerosas informaciones y opiniones sobre la cuestión de las lenguas. No hay duda de que en el plano político e institucional, la Transición fue el inicio del final del estado monolingüe concebido y ejecutado durante el franquismo, y se abrió la puerta a la diversidad lingüística, especialmente a lenguas como el catalán, el euskera y el gallego. En el plano macropolítico, el alcance del cambio era de gran calado: pasar de un estado ferozmente monolingüe, a un estado democrático abierto a promover todas las lenguas en sus respectivos territorios.

4. En la historia de la lengua dirigida por Cano, el excelente capítulo escrito por Brumme (2006), que entre otros temas trata el franquismo y la España salida de la Constitución de 1978, se centra en aspectos legislativos. Por su parte, la obra de Moreno Fernández (2005) dedica un capítulo a "Planes lingúísticos", en el que sitúa el tratamiento de las lenguas en la Constitución de 1931 y la de 1978, sin entrar a analizar a fondo lo que representó para las lenguas el franquismo y la Transición. La reciente historia del español dirigida por del Valle (2013), una de las aportaciones más recientes y novedosas que se han propuesto la renovación del relato historiográfico hispánico, no abarca por razones de corte temporal de la obra la etapa del franquismo y de la Transición. La historiografia lingüística catalana tampoco ha entrado a fondo en la cuestión, más allá de informaciones contextuales contenidas en obras generales como las de Ferrando y Nicolás (2011).

5. Véase, por ejemplo, el estudio La prensa en la transición española (1966-1978) de Castro Torres (2010), que resigue de un modo muy meticuloso las principales noticias y editoriales de muchas de las principales publicaciones periódicas (El País, Diario 16, Triunfo, Cuadernos para el Diálogo, Arriba, Ya, etc.). La referencia más importante de este estudio a las minorías se refiere a la organización territorial del Estado y a las negociaciones sobre el capítulo VIII de la Constitución (Castro, 2010: 305-308). No hay, sin embargo, ninguna referencia a lo que representan las lenguas durante la transición y al reflejo de este debate político y académico en la prensa. 
Sin embargo, una cosa fue el plano legal e institucional de las lenguas, y otra de muy diferente el debate público en los medios o las actitudes lingüísticas de los ciudadanos. Si durante la Transición varias lenguas encauzaron su condición de oficialidad y, en este sentido, se pondría fin al monolingüismo que había caracterizado el franquismo, esta ruptura a nivel legal no se convirtió en el foco principal del debate público. La mayoría de lectores que participaron en la opinión pública se centraron en otro tipo de temas, con más relevancia de uno u otro en función del contexto concreto de cada momento: cuestiones conceptuales relacionadas con las lenguas y los territorios (nación, región...), el uso de las lenguas en determinados acontecimientos culturales o las lenguas de la educación en las comunidades con lengua propia.

Todas estas cuestiones se van a analizar en los apartados sucesivos de este artículo, a partir de una aproximación que persigue relacionar los distintos niveles de intervención sobre las lenguas. Desde una concepción holística en el devenir de las lenguas, son varios los niveles a tener en cuenta: el nivel macrosocial (el plano legal y el institucional), el mesosocial (el que abarca desde las instituciones a la implementación de una política sectorial) y el microsocial (el que corresponde a los hablantes individuales y que puede abarcar desde el discurso público hasta las representaciones lingüísticas más variadas de los hablantes) 6 .

En una perspectiva histórica, estos tres niveles sociolingüísticos (micro, meso, macro) no actúan como compartimentos estancos y es todo un reto para el investigador entrelazar los varios niveles. El presente estudio parte del análisis del nivel microsocial o individual, lo que permite observar cómo se superponen los varios estratos y captar las distintas temporalidades, le temps long y le temps

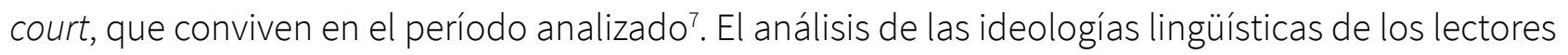
que se propone este estudio pone luz sobre los ritmos distintos del cambio: si en el plano legal la Transición supuso romper con el monolingüismo que caracterizó el franquismo, en el terreno de las actitudes individuales hacia las lenguas expresadas en el debate público hay no pocas continuidades, cuando no inercias que persisten. Esta aproximación ofrece una perspectiva sobre las lenguas durante la Transición que va más allá de lo que la literatura académica ha establecido hasta el momento, aunque haya cuestiones de carácter más general que desbordan los límites de este artículo. La riqueza y complejidad del tema va a necesitar de muchos estudios y aproximaciones. En el presente artículo me voy a centrar en una perspectiva microsocial, concretamente en el análisis de las ideologías lingüísticas expresadas por los lectores en las cartas al director publicadas en El País. Para ello, en primer lugar, voy a presentar brevemente el enfoque de las ideologías lingüísticas en

6. Para una concepción holística de la lengua, de acuerdo con las tendencias actuales en sociolingüística, véase, por ejemplo, Curdt-Christiansen (2016).

7. Para una enfoque teórico sobre las distintas concepciones del tiempo en los trabajos de sociolingüística histórica, véase el trabajo de Sara Cotelli (2009). Esta especialista defiende una aproximación histórica a las lenguas "plurielle, dynamique et multi-stratique", en la que se combinen por lo menos dos visiones sobre la temporalidad, "le temps long" y "le temps court". Este enfoque teórico se inscribe en un marco más amplio, el de la interpretación del tiempo en la historiografia y el de la visión de la historia como "continuidad" o como "ruptura". Sobre esta cuestión, véase, por ejemplo, Leduc (1999). 
el ámbito hispano. En segundo lugar, me voy a ocupar de la categorización y características de este texto periodístico para el análisis de la opinión. En tercer lugar, de lo que representó El País en sus inicios. En último lugar, voy a desarrollar mi análisis sobre las cartas al director (véanse apartados 2 y 3$)^{8}$. Este enfoque micro conduce, a su vez, a relacionar los varios niveles de análisis: a menudo, los lectores de los periódicos se sitúan en relación a los cambios macrosociales expresando su posicionamiento crítico o su actitud favorable. El punto de vista de los lectores es, pues, una excelente perspectiva que aúna el plano microsocial, individual en este caso, con los cambios propuestos, de corte más reformista o rupturista según los casos, por parte de los intelectuales, los movimientos sociales o las instituciones, tal y como se mostrará en el apartado 2.

Dentro de los estudios sobre las ideologías lingüísticas, existen corrientes muy diferentes, unas más próximas a la socio lingüística y a la antropología y otras más próximas a los estudios sobre el discurso o la comunicación (véanse las diferentes contribuciones teóricas de autores como Schieffelin et al. (1998); Wodak (1989); Kroskrity (2000) o Woolard (2008)). En el ámbito hispánico son de referencia las aportaciones de José del Valle (2007) y (2016), quien no solo ha emprendido obras analíticas dentro de este campo, sino que ha hecho un esfuerzo muy clarificador sobre los límites teóricos de esta corriente. Según la definición de del Valle (2016: 628) las ideologías lingüísticas son

sistemas de ideas que articulan nociones del lenguaje, las lenguas, el habla y/o la comunicación con formaciones culturales, políticas y/o sociales específicas. Aunque pertenecen al ámbito de las ideas y se pueden concebir como marcos cognitivos que ligan coherentemente el lenguaje con un orden extralingüístico, naturalizándolo y normalizándolo, también hay que señalar que se producen y reproducen en el ámbito material de las prácticas lingüísticas y metalingüísticas. ${ }^{9}$

Las piezas periodísticas de tema lingüístico y, en particular, las cartas al director representan una excelente muestra de la opinión de los ciudadanos en relación a las lenguas, tal y como se ha puesto de relieve en los estudios sobre "lingüística popular" o "lingüística de los legos"10. En lo que se referiere a su consideración dentro de la teoría de los géneros periodísticos, las cartas al director merecen valoraciones muy varias, a pesar de que son piezas fundamentales para el estudio de la opinión. Por una parte, son unos textos valorados por los profesionales del periodismo (son seleccionadas y editadas por el director o el editor, de aquí la noción de coautoría atribuida a dicho género) y, por

8. Dejo para otros estudios el análisis crítico de las informaciones y las opiniones acerca de las lenguas que los más varios periódicos españoles publicaron durante la Transición.

9. Definición ya propuesta anteriormente por el mismo autor en del Valle (2007: 20).

10. En el ámbito hispánico, destacan los trabajos de Lebsanft (1990, 1997 o 2017) dedicados a la cuestión, especialmente en relación a las actitudes de los hablantes respecto a la norma y al lenguaje periodístico. 
otra parte, son textos dirigidos implícitamente a la comunidad de lectores, aunque el director sea el lector explícito (Gomis, 2008 y Córdoba Jiménez, 2011)¹1.

Las funciones comunicativas de las cartas al director pueden ser muy varias (informativas, argumentativas, explicativas...), pero a menudo forman parte de un complejo universo discursivo configurado por artículos o columnas (para combatirlos, apoyarlos, matizarlos...) publicados por periodistas o intelectuales que colaboran regularmente en un periódico. No son pocas las cartas al director que comentan piezas informativas o de opinión (como respuesta a otras cartas al director o a columnas de opinadores regulares) publicadas en el mismo periódico o por otro. En este sentido, cabe destacar que dentro de nuestro corpus de cartas, un artículo de opinión de Federico Jiménez Losantos desencandenó varias reacciones, favorables o contrarias, e incluso se abrió un debate entre los lectores que participaron en la polémica, como se va a analizar en el apartado 3.1. Así pues, las cartas al director participan de una intertextualidad que configura, en su conjunto, la opinión pública.

En cuanto a la prensa española en el contexto de la Transición, cabe tener en cuenta los cambios que conllevó dicho perío do: el mapa comunicativo se reorganizó con la creación de nuevos rotativos. De aquellos años son, por ejemplo, los periódicos Diario 16, El Periódico de Catalunya, Avui o El País. Este último nace el 4 de mayo de 1976 bajo el impulso empresarial de PRISA, constituida 4 años antes. El núcleo fundacional lo constituyeron José Ortega Spottorno, Carlos Mendo, antiguo periodista de ABC, Darío Valcárcel, un aristócrata vinculado a la causa de Estoril, y Jesús de Polanco. Concebido como diario liberal conservador, se materializó como periódico liberal progresista o social-liberal, línea marcada por su director Juan Luis Cebrián, antiguo subdirector del periódico Informaciones y director de informativos de TVE ${ }^{12}$.

En la sección de cartas al director de este periódico, varias decenas de ciudadanos expresaron su opinión acerca de las lenguas. Tenemos la suerte de contar con el excelente estudio emprendido por Franz Lebsanft (1990), que ofrece un análisis crítico y exhaustivo sobre la cuestión. En pocos años, entre mayo de 1976 y 1986, El País publicó hasta 591 cartas al director sobre tema lingüístico. En la monografia del profesor alemán, los datos son también muy relevantes concretamente en cuanto a los años 1976 (desde mayo) y 1982: en este corto lapso de tiempo, el periódico liberalprogresista

11. No hay unanimidad entre los autores a la hora de situar este tipo de piezas. No son pocos los que omiten las cartas al director a la hora de caracterizar los principales géneros periodísticos. Para algunos autores, las cartas al director ni tan siquiera se podrían considerar con propiedad un género periodístico, pues se les cuestiona la autoridad informativa (no son escritas por profesionales del periodismo) y el control del lenguaje periodístico (Yanes, 2004). Finalmente, para otros teóricos los lectores en general son considerados como copartícipes de la cualidad de la información y la opinión de un periódico. Sea como fuere, en el mundo profesional, todos los periódicos incluyen una sección específica, algunos desde sus orígenes, como el propio diario El País. En las mejores tradiciones periodísticas, como la anglosajona, el protagonismo de los lectores puede llegar a ser del más alto nivel: en un periódico de tanta solera como The Times, incluso se han publicado en portada cartas al director. Para una revisión crítica sobre esta cuestión, véase Córdova Jiménez (2011).

12. Avui fue el primer periódico editado en catalán desde el año 1939. Véase la historia del periodismo español de Juan Francisco Fuentes y Javier Fernández Sebastián (1997). Sobre El País durante la Transición, véase Sueiro Seoane (2009). 
publicó hasta 226 cartas al director sobre tema lingüístico, de las cuales unas 60 se podría considerar que están relacionadas más o menos directamente con la diversidad lingüística.

\section{Ideologías lingưísticas de los lectores}

El enfoque argumentativo de los lectores está directamente asociado al contexto cultural o político de cada momento. En el estudio sobre las ideologías lingüísticas, en palabras de del Valle (2016: 628), es muy pertinente "el modo en que este contexto les confiere pleno significado". Las opiniones sobre las lenguas defendidas por los lectores de El País evolucionan a medida que el contexto sociopolítico cambia: el tipo de debate de los años 1976 y 1977, por ejemplo, es sustancialmente diferente del que se producirá una vez se haya implantado la democracia. De modo auxiliar, y para dar un enfoque contrastivo, se van a analizar cartas al director de periódicos españoles de otras sensibilidades, como va a ser con el caso de Pueblo. Las ideologías lingüísticas de la Transición no fueron, sin lugar a dudas, ni lineales ni monolíticas.

En los siguientes apartados vamos a abordar en qué medida los lectores a través de sus cartas al director ayudaron "a naturalizar un determinado orden social, es decir, a crear una apariencia de inevitabilidad asociada con un grupo particular de categorías y procesos culturales, políticos o sociales" (del Valle 2016: 628). Dicho en otros términos, vamos a analizar qué tipo de opiniones y posicionamientos tuvieron los lectores en relación a los nuevos cambios que comportó la Transición en cuanto al fin del monolingüismo del franquismo y al inicio del reconocimiento y promoción de todas las lenguas de España.

\subsection{Las lenguas y su relación con aspectos políticos y teóricos}

A menudo las cartas al director de tema lingüístico están directamente relacionadas con los debates del momento, especialmente con todos aquellos que tienen que ver con el proceso de definición del futuro estado democrático autonómico. Durante los primeros años de la Transición, las cartas se centraron en aspectos bastante generales, incluso teóricos, como la denominación de las distintas variedades lingüísticas ('lengua nacional', 'lengua regional', 'dialecto'...), o la relación entre lengua e identidad. Obviamente, esta preocupación está íntimamente ligada a la definición en curso del futuro estado democrático, impulsada por las reformas políticas emprendidas durante los primeros años de la Transición: el estatus de las futuras lenguas tiene una relación directa con la cuestión territorial y la concepción del modelo de Estado y de nación. En cuanto a los argumentos que los lectores suelen aducir, unos apoyan su opinión sobre su interpretación de la historia, mientras que otros fundamentan su autoridad en académicos a los que se les atribuye un prestigio en su campo. 
Dentro de las cartas al director de enfoque más teórico, hay lectores que recurren a la distinción entre los adjetivos 'nacional' y 'regional' aplicados a las lenguas para defender la supremacía del castellano en España. El lector César Verilla de las Heras argumenta esta noción teórica desde su propia interpretación de la historia de las lenguas en España:

\begin{abstract}
Me llevé las manos a la cabeza cuando la "nacionalización” de idiomas que, como el vasco y el catalán, jamás fueron nacionales. Aparte el castellano, el único idioma que tuvo expansión de carácter nacional fue el galaico-portugués, idioma de uso corriente en tiempos de Alfonso el Sabio (lo usaba para el verso), pero que sin necesidad de decreto alguno de nacionalización, fue casi literalmente barrido por el castellano, precisamente en una época de decadencia política de Castilla [...] Algo parecido debió suceder al catalán y a los demás idiomas y dialectos levantinos. No conozco ningún decreto ni pragmática de los siglos XVI ó XVII ordenando el uso obligatorio del castellano o prohibiendo el uso de cualquiera de los otros idiomas peninsulares. Y lo cierto es, que ningun otro idioma tiene en España carácter nacional. En castellano existe la única épica de carácter nacional, además del Romancero. [...] No debieran olvidar los regionalistas que el castellano además de idioma nacional y universal (gracias a su literatura, que se cuenta entre las mejores hazañas del espíritu humano), es idioma regional y local mayoritario en todas y cada una de las regiones y pueblos de España. Y ese carácter no lo alcanzó en virtud de ningún decreto, sino por la propia fuerza expansiva del idioma (César Verilla de las Heras, “Idiomas nacionales y regionales", EP, 11 de agosto de 1976) ${ }^{13}$
\end{abstract}

Hay otros lectores que se centran en la interpretación de la historia de las lenguas para posicionarse respecto al momento presente. En este sentido, el caso del lector José Miguel de Azaola es el más claro: quiere ser una respuesta a un artículo de opinión sobre el renacer de la lengua vasca firmado por Carlos Santamaría. El lector discrepa de Santamaría acerca de las consecuencias positivas de la persecución del vasco durante el franquismo. Para el lector Azaola, la persecución no ha sido "a la larga" benefeciosa para el vasco, sino que suposo "frenar en seco el movimiento expansivo, de cultivo y enseñanza de la lengua vasca", a fuer de haber sembrado "en ciertos ambientes irresponsables de Vasconia... un espíritu de revancha lingüística, de traza inconfundiblemente bélica” (“Guerra de idiomas?", EP, 6 de marzo de 1977)

La autoridad del columnista se vió seriamente cuestionada en la carta del lector R. Ventura Melià, quien respondió al artículo de opinión "Lenguas nativas y sistema educativo” de José Blat Gimeno (27 de julio 1977). El lector cuestiona su visión de las lenguas y defiende la existencia de un estado con cuatro lenguas nacionales fundamentándose en los sociolingüistas catalanes de la época:

13. Todas las cartas al director que se analizan en el presente articulo están referenciadas en Lebsanft (1990). Además de ser un completo y meticuloso catálogo sobre las cartas publicadas, el hispanista alemán ofrece una interpretación contextualizada respecto a la cuestión lingüística en España, sobre la base de un gran corpus debidamente tratado, con resúmenes de todas las "cartas", indíces analíticos de autores de "cartas", autores mencionados, índice de palabras e índice de temas lingüísticos tratados. 
Hablar de «lenguas nativas», de «lenguas maternas», de «lenguas regionales» y solfear sobre «bilingüismo» es mostrar una empanada mental paternalista sin ningún apoyo científico, y con resabios de integrismo político.

Si algo queda ya claro es que este estado alberga cuatro nacionalidades. Cualquier "región" pertenecerá a una de ellas. No hay "lenguas regionales" sino "lenguas nacionales" [...]

El "bilingüismo" es una ideología del bloque dominante, así nos lo han descubierto Aracil, Ninyoles, Badia Margarit y Vallverdú (a quienes debería leerse este verano aún). Aquí hemos padecido y padecemos una situación «diglósica», no de «igualidad», sino de «dominación». No hay enseñanza bilingüe que sea. No la queremos nosotros. Queremos aprender en nuestra lengua y nuestra lengua, pero ya.

En un contexto lingüísticamente complejo como el catalán, la sociolingüística académica conoció una divulgación social importante, que superó sin lugar a dudas los límites universitarios. A modo de ejemplo, uno de los libros superventas de la década de 1970 fue la obra Dues llengües, dues funcions? del sociolingüista Francesc Vallverdú. La carta al lector analizada es un buen reflejo, pues, del impacto popular de esta disciplina universitaria entre la población informada.

Las ideologías lingüísticas que expresan numerosos lectores de El País también se encuentran en otros periódicos de la época. Nótese que ningún lector de El País cuestiona la cooficialidad de las lenguas no castellanas. Este tipo de planteamiento, en cambio, sí se encuentra en periódicos conservadores. Valga como ejemplo el análisis de un par de piezas publicadas en Pueblo. Tal y como se acaba de mostrar, las cartas a los lectores pueden venir motivadas por aspectos del contexto político general. Este es el caso del lector Anselmo Cid, un gallego residente en París profesor en la Universidad de La Sorbona que dice pasar sus "vacaciones en Gandía, donde ya empiezo a sentirme tan extranjero como en Francia”. Este lector parte del modelo de Estado que se está discutiendo (el modelo autonómico, con el que dice estar en desacuerdo), para expresar su opinión acerca de las lenguas: "cuando oigo hablar del gallego, catalán, valenciano y vasco como lenguas oficiales me siento herido en lo más hondo del alma" (Cid, Anselmo, "El desmadre de las autonomías", Pueblo 02 de septiembre de 1977).

Antes de la Constutición y de los estatutos que se derivarán de ella, hay lectores que intuyen que la cooficialidad irá de par con obstáculos para el ascenso social sin el previo conocimiento de la lengua de la comunidad. El lector Antonio Ruiz-Giménez alerta en Pueblo sobre "un grave problema” que va a suponer la cooficialidad del catalán, el del freno al ascenso social por parte de los ciudadanos castellanoparlantes de Cataluña: "Las plazas vacantes en bancos, oficinas y establecimientos comerciales nos están totalmente vetadas, y, por mucho que sepas, has de conformarte con puestos míseros" (“Discriminación en el trabajo", Pueblo, $1^{\circ}$ de marzo de 1977). 
Sería muy interesante explorar a fondo las reacciones de los lectores de todo tipo de periódicos y calibrar hasta qué punto hay una relación entre la orientación ideológica, o ámbito territorial de un periódico, y el tono general de las ideologías lingüísticas que sus lectores sostienen: críticas a la oficialidad, defensas de la lengua nacional, críticas a la diversidad, etc. Sin embargo, esta cuestión desborda los planteamientos del presente estudio y habrá que esperar a que futuros estudios cubran este terreno de investigación.

\subsection{Las lenguas y su relación con acontecimientos culturales}

Además de las cartas dedicadas a aspectos generales y teóricos, en El País también las hay que opinan sobre acontecimientos culturales del momento que suponen una novedad. En este sentido, un recital en catalán de Lluís Llach retransmitido por TVE, la reivindicación del catalán en el PEN Club celebrado en Estocolmo o incluso la fiesta del libro fueron motivo de que varios lectores escribieran al periódico.

Lluís Llach dio un concierto en el teatro Grec de Barcelona en 1974 y al cabo de dos años, TVE lo retransmitió. Este acontecimiento cultural provocó reacciones opuestas. Desde Ciudad Real la lectora M. Teresa Ontiveros pedía que la televisión hubiera tenido que "incluir unos subtítulos" para que los ciudadanos que no entendían las letras pudieran disfrutar más de "un cantante auténticamente interesante" "“El recital de Lluís Llach", EP, 19 de diciembre de1976). Por su parte, el lector Melchor Enrique Asenjo exclamaba desde Madrid que una cosa era "que desde hace algún tiempo ya no es pecado de leso españolismo hablar, escribir o cantar en catalán", pero otra muy diferente era "sacar al Lluís Llach en sábado y por la primera cadena para soltarnos sus canciones como si tal cosa hay un abismo que hace unos meses parecía imposible de cruzar" ("Un repentino y sospechoso amor por Cataluña", EP, 19 de diciembre de 1976). Parece claro que ante el monopolio del castellano en la televisión pública, la retransmisión de un concierto de música en catalán era percibida como una rareza e incluso una sorpresa por una parte del público. La televisión pública de la época hubiera podido preparar al público para recibir con normalidad un acontecimiento de estas características y aprovechar la ocasión para hacer pedagogía de la diversidad como una riqueza a potenciar en el futuro estado democrático.

En cuanto al PEN Club celebrado en Estocolmo, el lector Jesús Torbado utiliza un tono sarcástico para criticar la reivindicación del catalán como lengua de los escritores catalanes representados en la asociación internacional de escritores.

Los delegados catalanes en la conferencia del Pen Club (Club Internacional de Escritores) se opusieron a que el castellano fuese considerado lengua oficial de la institución, ya que únicamente es hablado por trescientos millones de analfabetos y cultivado por algunas docenas de resentidos plumíferos del planeta. Aunque la propuesta parecía bien a todo el mundo, incluídos los que escriben en swahili, que son africanos antiimperialistas, los catalanes la 
consideraron una ofensa para su país y para su pueblo por tratarse de la lengua sojuzgadora (“El circo catalán”, EP, 16 de junio de 1978).

En un modo mucho más explícito, el lector Albert Burgos Baruel denunciaba la falta de atención de los medios hacia el día de Sant Jordi y defendía su españolidad justamente por su condición de catalanoparlante (y "nacionalista"):

Permítame expresar en su diario mi más enérgica protesta, principalmente como español. Yo soy catalán, nacionalista, pero, como tal, también soy español, porque ser español es ser: gallego, andaluz, aragonés, catalán, etc. Ser español es sencillamente convivir todos juntos y estructurarnos libremente como Estado. Ser español no quiere decir tener que hablar sólo castellano, ni propugnar una celestial unidad carente de realidades más concretas y libres que libremente la constituya. [...]

Yo estaba también el día de Sant Jordi en la plaza de Sant Jaume pidiendo, en mi lengua, el Estatut (volem l'Estatut) y pensando, en catalán, soñé con una España nueva (“Cataluña y España", EP, 22 de mayo de 1977).

En este caso, la celebración de un acontecimiento festivo y cultural como el día del libro deriva hacia una opinión que mezcla lengua, identidad y el modo de concebir el Estado. Los acontecimientos culturales de signo diverso no estaban exentos de cargas extraculturales a la luz de las opiniones de los lectores.

\section{Ideologías lingưísticas de los lectores al inicio de la democracia}

Las ideologías lingüísticas de los lectores evolucionan en muy pocos años hacia nuevos temas y nuevos argumentos. Si al principio de la Transición dominan los temas generales y las relaciones entre lengua e identidad, a partir de 1979 se puede observar un cambio de orientación, sin duda ligado a las primeras concreciones institucionales y legislativas del nuevo Estado democrático. Por un lado, hay varios lectores que, con matices y argumentos diferentes, ponen el acento en el derecho de los inmigrantes castellanoparlantes en Cataluña y, por el otro, hay varios lectores que denuncian las incipientes políticas lingüísticas en democracia, al considerarlas lesivas respecto a los derechos lingüísticos, especialmente en el terreno de la educación en sus distintos niveles. En todos estos casos, el lector suele autodefinirse en términos lingüísticos, identitarios y políticos para dar validez a la argumentación general que defiende: son frecuentes las cartas en las que el lector se presenta como "catalanoparlante", "castellanoparlante", "no separatista”, "nacionalista”, etc. (Ya hemos visto que este tipo de autoidentificación también se explicitaba, de vez en cuando, en algunos modelos de carta analizados anteriormente.) 


\subsection{Los derechos de los castellanoparlantes}

En relación a la reivindicación de los derechos de los inmigrantes en comunidades con lengua propia, las primeras cartas sobre el tema son reacciones a la publicación en El País de un capítulo del libro Lo que queda de España de Federico Jiménez Losantos. Hay lectores que expresan su rechazo a las tesis del periodista y otros que replican a los lectores contrarios al periodista aragonés. Montserrat Caballé es la primera lectora que escribe una carta para replicar las tesis de Jiménez Losantos recordándole el artículo sobre lenguas en el anteproyecto de Estatuto de Cataluña:

En vista de estas normas, ¿cómo puede el señor Jimériez afirmar que el castellano "es una causa perdida en Cataluña"? Si los propios catalanes garantizan su uso y conocimiento, cosa que el régimen de Franco no supo hacer con el idioma catalán, sino todo lo contrario. ¿Es que el señor Jiménez pertenece al antiguo partido único, lengua única, sindicato único? (“Lecciones de catalán", EP, 3 de febrero de 1979).

El lector Juan J. Aguado escribe desde Barcelona para dar su opinión sobre las ideas de Jiménez Losantos, y explica su biografia personal: se presenta como un castellanoparlante que lleva "trece años trabajando" en Barcelona y a quien no le parece mal el artículo sobre lenguas previsto para el Estatuto. Sin embargo, habla en nombre de "los inmigrantes” para denunciar la catalanización de los ámbitos públicos y el catalanismo de los partidos de izquierda:

A los inmigrantes se nos pide que nos integremos "voluntariamente" en la cultura catalana. Pongo las comillas porque en la realidad esa voluntariedad no es tal, debido a la presión psicológica que hay por catalanizar todo. Dada la desigualdad económica y de poder en que se encuentra el inmigrante, no le queda más remedio que renunciar a su idioma, si no quiere llegar a ser un ciudadano de segunda clase. Y cuando digo renunciar a su idioma, no me refiero al uso coloquial y familiar, sino al uso oficial, político y social, es decir, en estricta igualdad de derechos con el catalán.

$[\ldots]$

Y no es que los catalanes estén imponiendo su lengua a los castellanos, no. No es eso. Son los que tienen los resortes del poder en sus manos, partidos, entidades, intelectuales..., los que están llevando a cabo esta política de asimilación. La responsabilidad histórica de los partidos de izquierda, como principales beneficiarios de los votos de los inmigrantes, es muy grave. ("Los emigrantes y el catalán”, EP, 21 de febrero 1979)

Por su parte, el lector Jesús Rodríguez Velasco se adhiere a las opiniones expresadas por Aguado y habla de "represión catalanista" (titulo de su pieza) y de "la actual integración dictatorial del charnego (xarnec)", "donde todo andaluz quiera o no quiera tiene que hablar una lengua extraña, olvidando la suya que se extiende desde el norte de Africa a la Tierra del Fuego". Rodríguez, que escribe desde Madrid, se presenta como un "trabajador inmigrante que sufrió en sí mismo y en su familia una serie de penalidades, sin cuento”. En su ataque a la incipiente catalanización de la sociedad, enumera va- 
rios ejemplos: desde recordar que "su verdadero nombre [del catalán] es lemosín", hasta las clases en catalán en la Universidad o el mantenimiento de esta lengua en presencia de castellanoparlantes. El lector cierra su carta de modo apocalíptico: "Como los catalanistas no saben bien el castellano y los andaluces no tienen idea del catalán, se está formando una mezcla de catalán-andaluz, que no hay cristiano que entienda y va en perjuicio de la pureza de ambas lenguas." "'La represión catalanista", EP, 23 de febrero de 1979). Esta carta es respondida por el lector Josep M. Ramis, que rebate la tesis lemosinista de Rodríguez apelando a autoridades filológicas como Josep Melià y Joan Coromines, y defiende la oficialidad del catalán y el derecho a hablarlo:

Es incómodo y difícil, para el inmigrante, aprender un nuevo idioma. Algo más que incómodo y difícil es que a un catalán se le niegue el derecho a hablar su propia lengua, como ha venido pasando estos últimos años ("Sobre el catalán", EP, 27 de febrero de 1979).

También se muestra a favor de las tesis de Jiménez Losantos la lectora Paula Farret, que se presenta como "persona catalana de origen y lengua... casada con castellano": afirma sentirse abochornada por "la campaña de mentalización catalanista a que se viene sometiendo a la gente de fuera" y cuestiona que se "obligue a hablar catalán a quienes tienen un idioma tan rico como el castellano" (“Entre castellano y catalán”, EP, 10 de julio de 1979).

\subsection{Lenguas de la enseñanza y debate en torno al bilingüismo y a la normalización}

A medida que el nuevo Estado democrático se va cada vez más concretando y desarrollando, más frecuente es la denuncia de las incipientes políticas lingüísticas autonómicas, al considerarlas lesivas respecto a los derechos de los castellanoparlantes, especialmente en el terreno de la educación en sus distintos niveles. En este sentido, se expresan varios lectores.

Rafael Ávila, que se presenta como un "licenciado en Filosofía y Letras por Salamanca [que] resid[e] en Cataluña desde hace seis años, siendo natural de Andalucía", explica su experiencia personal en el mundo laboral para denunciar que el hecho de no hablar catalán resulta "un obstáculo casi insuperable" para obtener trabajo en Andorra o en Cataluña ("Castellanohablante en Cataluña", EP, 7 de septiembre de 1979). Esta carta es contestada desde Andorra por el lector J.R. Serra, quien aconseja que "después de seis años, lo más correcto, lo más eficaz e incluso lo más inteligente, para un licenciado en Filosofía y Letras es que, si vive en Cataluña, aprenda catalán”. Serra también recurre a su experiencia personal, pero en su caso para defender que se debe aprender la lengua del país donde se vive, como lo hacen los trabajadores "franceses, portugueses y andaluces" que trabajan en su empresa: "Hablan catalán y así convivimos con un problema menos los hombres y las tierras de España..., perdón, de Europa” ("Castellano-hablante en Cataluña y... Andorra”, EP, 9 de septiembre de 1979). 
Hay numerosas cartas de lectores que critican las políticas lingüísticas de los territorios con lengua propia, incluso antes de aprobarse los respectivos estatutos de autonomía y las leyes de política lingüística que se derivarán posteriormente. Sobre este tema, las quejas proceden de varias CCAA y no solo de Cataluña, como en la mayoría de los casos vistos hasta ahora. Ya en 1977 un lector de Guipúzcoa se quejaba de la exclusión de un castellanoparlante en una ikastola ("Discriminación al revés", EP, 23 de abril de 1977). El lector Luis Miguel Jiménez Benito, por su parte, consideraba que la inversión del Estado en la enseñanza de "lenguas vernáculas" se debería compensar con "un esfuerzo [presupuestario] similar en otras regiones o nacionalidades" ("Lenguas vernáculas", EP, 3 de septiembre de 1980). Ante las informaciones publicadas en la prensa acerca de la preparación de la ley de política lingüística en Cataluña, el lector Manuel Villoslada veía en ella una amenaza para "la desaparición del bilingüismo" y alertaba de que no incurriera "en fallos discriminatorios que perjudiquen al medio de expresión hablado y escrito de la comunidad castellano-hablante, representada nada menos que por la mitad aproximada de la población de Cataluña" ("El enriquecedor bilingüismo", EP, 18 de julio de 1980). Este artículo mereció la respuesta desde Andorra del lector J. Ros Serra, quien le replicó que

el único bilingüismo total que existe es el de los catalanes. Es un bilingüismo enriquecedor y acorralado al tiempo. Los castellanohablantes deben ser en su mayoría partidarios de la pobreza, cuando no sólo en Cataluña rehusan la lengua de adopción, sino que la rehusan también en Andorra, donde es la única lengua oficial. ("Dos lenguas", EP, 29 de julio de 1980).

El proceso de normalización del catalán ya fue cuestionado de arriba abajo incluso unos años antes de la primera ley aprobada por el Parlamento de Cataluña, que fecha de 1983. Unos años antes, los lectores Juan Carlos Torrubia y Maria Mercè Sans, consideraban que la normalización "pretende despojar de su lengua y cultura a cientos de miles de inmigrantes, que constituyen la mitad de la población de Cataluña" "“Cooficialidad de las lenguas", EP, 7 de agosto de 1979). En algunos casos, se critica la normalización del catalán para criticar a los partidos catalanistas de izquierda y en palabras de los lectores Juan Carlos Torrubia y Maria Mercè Sans, "dar la bienvenida al PSA o cualquier otro partido del resto del Estado que defienda el derecho a la cultura y lengua propias de dos millones y medio de personas que viven y trabajan en Cataluña." "'Cooficialidad de las lenguas", EP, 7 de agosto de 1979).

Hay varios lectores que entran en un terreno más concreto y plantean la lengua de la enseñanza. El lector Aurelio Pérez Fustegueras pedía un sistema educativo "duplicado, es decir, escuela, instituto y universidad catalanes, por un lado, y escuela, instituto y universidad castellanos, por otro" ("Más sobre idioma", EP, 14 de agosto de 1980). La lectora Rosa María Carretero pedía en cualidad de maestra poder impartir en castellano varias asignaturas en las Islas Baleares y se hace muchas preguntas en cuanto a sus derechos lingüísticos individuales y a los de los castellanoparlantes en general: 
“No se puede enseñar las matemáticas o las ciencias en castellano, que al fin y al cabo es un idioma que tienen que aprender también? ¿O es que quizá tendrán que contruirse en Baleares colegios para niños españoles, separados de los colegios para niños mallorquines o ibicencos...? ¿Es que un español de la Península no puede abrirse camino en las islas españolas aunque con ello tenga que aprender mallorquín, pero con el tiempo? ¿Primero debe estar un año sin trabajar dedicándose a aprender mallorquín y luego puede ir allí?” (“Enseñanza en las nacionalidades", EP, 10 de julio de 1979).

El lector Antonio Cabezuelo utilizaba un lenguaje denigrante hacia las lenguas no castellanas al denunciar que "para ir a España, tenemos que ir a la escuela para aprender los dialectos, porque este año he estado en Barcelona y hasta las calles las han cambiado. Y en Palma y Valencia, igual. Y aún nos dicen que tenemos que esforzarnos por aprender". El lector escribe desde París y no duda en expresar su nacionalismo lingüístico: "Aquí, en el extranjero, tenemos que soportar la lengua del país, pero cuando vamos a España nos gusta poder hablar nuestra lengua, que para nosotros es la mejor". Cierra su carta para mostrarse "en contra de los dialectos" y para pedir que España se ponga "al nivel del mundo, porque aquí, en Francia, hay más dialectos, pero sólo se habla la lengua del país” (“Un solo idioma”, EP, 26 de septiembre de 1980).

El lector Manuel Villoslada criticaba la normalización desde el punto de vista de los problemas académicos de los alumnos y denunciaba que "muchos niños castellanohablantes han sido suspendidos en la asignatura de lengua catalana, impuesta, y que incluso en la universidad (me consta que así es en la Autónoma) los estudiantes de habla castellana no pueden seguir normalmente sus clases por dárselas en catalán". ("Más sobre bilingüismo", EP, 8 de agosto de 1980). Todavía en un terreno más concreto y más personal, se expresaba el lector Juan José Aguado, quien denunciaba la catalanización de las guarderías en Barcelona, donde "a pesar de visitar siete u ocho guarderías, en todas ellas la enseñanza y el trato colectivo ha de hacerse en catalán”. Aguado, que se presenta como un cántabro residente en Barcelona desde hacía 14 años, buscaba para su hijo una guardería "en la que se le empiece enseñando en castellano como primera lengua y luego, progresivamente, el catalán” (“Bilingüismo”, EP, 3 de abril de 1980).

Junto a las numerosas críticas a los cambios lingüísticos que se abrían con la España democrática, son solo unos pocos lectores de El País los que muestran su conformidad con las políticas lingüísticas autonómicas. Así lo expresa desde Logroño José María Ruiz en su carta al director. En la medida en que es un posicionamiento minoritario entre las cartas al director y en este caso procede de un territorio sin lengua propia, merece la pena reproducir su opinión de modo extenso:

El castellano es el idioma oficial de España, y todos los españoles tienen que conocerlo, sea cual sea su lengua materna. De acuerdo, pero el catalán es también -tanto como el castellano- idioma oficial del principado y todos los ciudadanos de Cataluña tienen que conocerlo, sea cual sea su lengua materna. Así de sencillo. Por supuesto que no se puede exigir de sopetón el conocimiento del catalán a la población inmigrante adulta, pero sí poco a poco, 
y desde ahora mismo, a las nuevas generaciones (“Más sobre idioma”, EP, 14 de agosto de 1980).

También tiene una opinión positiva el lector Jorge Madueño, quien escribe desde Bilbao para expresar su posición favorable al decreto-ley sobre bilingüismo, pues "tiene derecho el pueblo vasco a hablar su lengua y a poseer su propia bandera, que las tiene" ("A favor del euskera", EP, 9 de mayo de 1979).

Obsérvese, pues, que la mayoría de posicionamientos favorables a los cambios lingüísticos que se dieron con la implantación del nuevo Estado democrático son réplicas a cartas al director por parte de lectores, como el caso del lector J. Ros Serra, que expresan su desacuerdo con algún lector que previamente había escrito al periódico para quejarse sobre algún aspecto que ponía en cuestión la hegemonía del castellano, ya fuera en aspectos generales, ya fuera en ámbitos varios de la vida social, como la educación. La actitud positiva ante los cambios lingüísticos que se abrieron durante la Transición fue una expresión muy minoritaria dentro del conjunto de cartas al director.

\section{Conclusiones}

En los momentos de cambio sociopolítico las sociedades tienden a plantearse las bases sobre las que se habían fundamentado hasta un cierto momento. La Transición fue un período de profundas transformaciones que han dejado una honda huella en la España actual, por lo que ha merecido, sin cese, el interés de las más varias aproximaciones académicas (políticas, sociales, culturales...). En el terreno de las lenguas, la literatura académica sobre la cuestión se ha centrado en los cambios en el plano legislativo y en este sentido, ha puesto de relieve que la Transición supuso poner fin al monolingüismo instaurado por el franquismo y abrir una etapa de reconocimiento a la diversidad lingüística. Desde esta perspectiva, la Transición puede considerarse como el inicio de la de ruptura. Ahora bien, si se enfoca la cuestión desde el terreno de las ideologías lingüísticas de los ciudadanos, la Transición aparece menos como un momento de ruptura y se muestra más como un período de continuidad, lleno de dudas y reticencias hacia una futura etapa democrática abierta a la diversidad. El marco interpretativo de las lenguas en el plano legal e institucional no encaja en el análisis de las ideologías lingüísticas expresadas por los lectores en la prensa, que requiere de otras aproximaciones y otros parámetros interpretativos.

Este artículo pretende abrir una serie de estudios que planteen qué papel jugó la prensa a la hora de propiciar un cambio de mentalidades en el paso del franquismo a la democracia. Para ello, cabrá analizar en otros estudios las informaciones y las opiniones que se expresaron en los más variados periódicos españoles. En este artículo me he limitado a estudiar las ideologías lingüísticas de los lectores del periódico El País, expresadas a través de su sección de cartas al director. Durante unos pocos años, entre 1976 y 1982, se publicaron más de 200 cartas sobre el tema de la diversidad lingüística, una buena parte de las cuales están relacionadas con la diversidad lingüística. 
Las cartas al director, a pesar de ser un género periodístico académicamente controvertido, son un excelente termómetro para diagnosticar la opinión pública de los ciudadanos. Durante la Transición, los lectores de El País emitieron sus juicios en relación a las lenguas en estrecha relación a elementos de carácter extralingüístico, a veces relacionados con la evolución política, a veces con acontecimientos culturales muy varios. Como es propio en el estudio de las ideologías lingüísticas, hemos visto cómo la opinión y los juicios sobre las lenguas a veces están relacionados con el contexto, con las propias experiencias individuales y, naturalmente, con el posiconamiento de cada ciudadano en relación a su sociedad.

Las ideologías lingüísticas de la Transición no presentan un tono uniforme, sino que reflejan opiniones de todo tipo, a menudo antagónicas, sobre aspectos generales y teóricos (lengua nacional, dialectos, bilingüismo...), especialmente dominantes durante los primeros años de la Transición, pero también sobre temas más concretos relacionados con los primeros años de la democracia, tales como la promoción de las lenguas, la enseñanza o el planteamiento de los derechos lingüísticos en las comunidades con lengua propia. En un periódico tan importante durante la Transición como El País, la mayoría de sus lectores expresaron muchas reticencias, cuando no abierta oposición, a los cambios que conllevó la Transición respecto a varias lenguas. Entre las cartas al director, son minoritarios los planteamientos favorables a las incipientes políticas lingüísticas de las comunidades autónomas con lengua propia. La opinión pública española de la Transición todavía estaba ligada a las inercias monolingüistas del franquismo, aunque no fueron obstáculo para que en el plano legal y político se impulsara una promoción efectiva de varias lenguas en el espacio público, en la educación y en la vida social en general.

Si nos situamos en el binomio continuidad-ruptura, constitutivo de toda narrativa historiográfica, el presente artículo pone luz más sobre las continuidades que muestra la opinión pública española en relación a la diversidad lingüística, que sobre la ruptura que efectivamente se fraguó en el plano legal, tal y como ha subrayado hasta el momento la literatura académica. En cierto modo, el presente artículo ilumina una temporalidad, la de "le temps long", que ha quedado ocultada por la perspectiva macropolítica de la Transición como un período de ruptura o cambio radical. En este período tan complejo, coexistieron distintos planes y varias temporalidades, que a la luz del análisis sobre las ideologías lingüísticas de los lectores de prensa, proyectan con nitidez un nivel oculto para la mayor parte de la literatura académica y, a su vez, el carácter dinámico y multiestrático de la historia de las lenguas. 


\section{Referencias bibliográficas}

Bastardas, Albert y Emili Boix (eds.) (1994), ¿Un estado, una lengua? La organización política de la diversidad lingüística, Barcelona, Octaedro.

Benet, Josep M. (1995), L'intent franquista de genocidi cultural contra Catalunya, Barcelona, Publicacions de l'Abadia de Montserrat.

Brumme, Jenny (2006), "Las regulaciones legales de la lengua (del español y las otras lenguas de España y América)", en Rafael Cano (ed.), Historia de la lengua española, Barcelona, Ariel, p. 945972.

Castillo Lluch, Mónica y Johannes Kabatek (ed.) (2006), Las lenguas de España: política lingüística, sociología del lenguaje e ideología desde la Transición hasta la actualidad, Madrid/Fráncfort, Iberoamericana/Vervuert.

Castro Torres, Carmen (2010), La prensa en la transición española (1966-1978), Madrid, Alianza Editorial.

Córdova Jiménez, Alejandro (2011), “Las cartas al director como género periodístico”, ZER, n³0, p. 189-202.

Cotelli, Sara (2009), "Sociolinguistique historique: un tour d’horizon théorique et méthodologique", en Dorothée Aquino-Weber, Sara Cotelli y Andres Kristol (eds.), Sociolinguistique historique du domaine gallo-roman: enjeux et méthodologies, Berne, Peter Lang, p. 3-24.

Curdt-Christiansen, Xiao Lan (2016), "Conflicting language ideologies and contradictory language practices in Singaporean bilingual families", Journal of Multilingual and Multicultural Development, n³7, vol. 7, p. 694-709.

Del Valle, José y Vitor Meirinho-Guede (2016), "Ideologías lingüísticas”, en Javier Gutiérrez-Rexach (ed.), Enciclopedia de Lingüística Hispánica, New York, Routledge.

Del Valle, José (2007), La lengua, ¿patria común? Ideas e ideologías del español, Madrid/Fráncfort, Iberoamericana/Vervuert.

Del Valle, José (2013), A Political History of Spanish: The Making of a Language, Cambridge, Cambridge University Press.

Ferrando, Antoni y Miquel Nicolás (2011), Història de la llengua catalana, Barcelona, UOC.

Fuentes, Juan Francisco y Javier Fernández Sebastián (1997), Historia del periodismo español: prensa, política y opinión pública en la España contemporánea, Madrid, Síntesis.

González Ollé, Fernando (1978), "El establecimiento del castellano como llengua oficial”, Boletín de la Real Academia Española, vol. 58, n²14, p. 231-282.

Gallofré i Virgili, Maria Josepa (1991), L'edició catalana i la censura franquista (1939-1951), Barcelona, Publicacions de l'Abadia de Montserrat. 
Gomis, Lorenzo (2008), Teoría de los géneros periodísticos, Barcelona, UOC.

Iglésias, Narcís (2019), "Language policies in contemporary Catalonia: a history of linguistic and political ideas", en Pompeu Casanovas, Montserrat Corretger y Vicent Salvador (eds.), The rise of Catalan identity: social commitment and political engagement in the twentieth century, Cham, Springer, p. 79-105.

Kroskrity, Paul V. (2000), "Regimenting languages: Language ideological perspectives", en Paul V. Kroskrity (ed.), Regimes of language: Ideologies, polities, and identities, Santa Fe, School of American Research, p. 1-34.

Lebsanft, Franz (1990), Spanien und seine Sprachen in den Cartas al Director von El País (1976-1987): Einführung und analytische Bibliographie, Tübingen, Günter Narr Verlag.

Lebsanft, Franz (1997), Spanische Sprachkultur: Studien zur Bewertung und Pflege des öffentlichen Sprachgebrauchs im heutigen Spanien, Tübingen, Niemeyer.

Lebsanft, Franz (2017), "Lingüística populary codificación del español”, en Wolfgang Dahmen, Günter Holtus, Johannes Karmer, Michael Metzeltin, Claudia Polzin-Haumann, Wolfgang Schweickard y Otto Winkelmann, Sprachkritik und Sprachberatung in der Romania: Romanistisches Kolloquium XXX, Tübingen, Narr Francke Attempto, p. 103-118.

Leduc, Jean (1999), Les historiens et le temps: conceptions, problématiques, écritures, París, Seuil.

Marcet, Joan (2013), “La política lingüística de l'Estat Espanyol: una aproximació a la incomprensió del pluralisme cultural", Revista de Llengua i Dret, n59, p. 59-74.

Moreno Fernández, Francisco (2005), Historia social de las lenguas de España, Barcelona, Ariel.

Pericay, Xavier (ed.) (2007), ¿Libertad o coacción? Políticas lingüísticas y nacionalismos en España, Madrid, FAES.

Sánchez Erauskin, Javier (1994), El nudo escurridizo: Euskal Herria bajo el primer franquismo, Tafalla, Txalaparta.

Schieffelin, Bambi B., Kathryn A. Woolard y Paul V. Kroskrity (eds.) (1998), Language ideologies: practice and theory, New York/Oxford, Oxford University Press.

Sueiro Seoane, Susana (2009), "El papel del diario El País en la Transición”, en Rafel Quirosa-Cheyrouze y Muñoz (ed), Prensa y democracia: los medios de comunicación en la Transición, Madrid, Editorial Biblioteca Nueva, p. 151-160.

Tusell, Javier (1997), La Transición española: la recuperación de las libertades, Madrid, Temas de Hoy.

Wodak, Ruth (ed.) (1989), Language, power, and ideology: studies in political discourse, Amsterdam, John Benjamins.

Woolard, Kathryn (2008), "Les ideologies lingüístiques: una visió general d'un camp des de l'antropologia lingüística", Revista de Llengua i Dret, nº 49, p. 179-199. 
Yanes, Rafael (2004), Géneros periodísticos y géneros anexos: una propuesta metodològica para el estudio de los textos publicados en prensa, Madrid, Fragua.

Ysàs, Pere (2013), "Ni modèlica ni immodèlica. La transició des de la historiografia", Franquisme \& Transició, n 1, p. 273-308. 